\title{
MATOCOMPETIÇÃO NA CULTURA DE Crambe abyssinica CULTIVADO EM SAFRA E SAFRINHA
}

Suzete Fernandes Lima ${ }^{1 *}$, Paulo César Timossi ${ }^{2}$, Elias Brod ${ }^{3}$, Itamar Rosa Teixeira ${ }^{4}$, Janaína de Assis Silva ${ }^{5}$

\footnotetext{
${ }^{1}$ Engenheira Agrônoma, Mestre em Agronomia - Produção Vegetal, Doutoranda em Ciências Agrárias no Instituto Federal Goiano, Rio Verde - GO. *E-mail: suzete.lima@yahoo.com.br

${ }^{2}$ Professor na Universidade Federal de Goiás, Regional Jataí - GO.

${ }^{3}$ Engenheiro Agrônomo, Consultor técnico na TERRAN. Universidade Federal de Goiás, Regional Jataí - GO.

${ }^{4}$ Professor na Universidade Estadual de Goiás, Unidade de Anápolis - GO.

${ }^{5}$ Engenheira Agrônoma, Mestre em Agronomia - Produção Vegetal pela Universidade Federal de Goiás, Regional Jataí - GO.
}

\section{Recebido: 16/03/2017; Aceito: 22/06/2018}

RESUMO: A cultura do crambe (Crambe abyssinica) se destaca na região Centro-Oeste como uma opção de cultivo em segunda safra, com potencial para produção de biodiesel, além da possibilidade de ser inserida em programas de rotação de culturas. A espécie é originária do Mediterrâneo e possui poucas informações referentes ao seu potencial competitivo com as plantas daninhas, sobretudo no Brasil. Nesse sentido, objetivou-se determinar os períodos de convivência e controle entre plantas daninhas e a cultura de crambe, cultivado na safra e na safrinha. Em ambos os experimentos, os tratamentos experimentais, dispostos em esquema de blocos casualizados, constaram de períodos de controle e de convivência, a saber: $0,7,14,21,28,35,42,56$ e 70 dias após a semeadura. Pela análise fitossociológica, verificou-se que as plantas daninhas de maior importância durante a safra foram tigueras de Sorghum bicolor e Chamaesyce hirta, e no cultivo em safrinha, Chamaesyce hirta e Digitaria horizontalis. A convivência com a comunidade infestante não afetou negativamente o estande de plantas e a altura de crambe. Para a produtividade de síliquas, constatou-se interferência negativa apenas quando as plantas de crambe conviveram com a flora daninha por pelo menos 70 dias, durante o cultivo de safra. Dessa forma, pode-se concluir que a cultura de crambe é altamente competitiva, sendo possível apenas uma intervenção para que o manejo das plantas daninhas seja suficiente para manter a cultura sem apresentar interferência negativa, a qual pode ser realizada por ocasião da dessecação de pré-semeadura.

Palavras-chave: Fitossociologia. Plantas daninhas. Períodos de interferência.

\section{MATOCOMPETITION IN THE CULTURE OF Crambe abyssinica CULTIVATED IN CROP AND SECOND CROP}

ABSTRACT: The Crambe abysinica has excelled in the Midwest region as an option of second crop cultivation, with potential for biodiesel production, besides the possibility of 
being inserted in crop rotation programs. The species is native to the Mediterranean and has little information regarding its competitive potential with weeds, especially in Brazil. In this sense, the objective was to determine the periods of coexistence and weed control between and crambe crop, grown in season and off-season. In both experiments, the experimental treatments, arranged in a randomized block design, comprising periods control and interaction, namely: $0,7,14,21,28,35,42,56$ and 70 days after sowing. By phytosociological analysis, it was found that the weeds of greater importance during the harvest were Sorghum bicolor and Chamaesyce hirta. For cultivation in off-season, Chamaesyce hirta and Digitaria horizontalis were the main weeds present in the experimental area. Living with the weed community did not negatively affect the plant stand and $C$. abyssinica high. For siliques productivity, negative interference was observed only when the plant crambe coexisted with the weed flora for at least 70 days, during crop cultivation. Thus, it can be concluded that the crambe culture is highly competitive, and it is possible that only one intervention for the management of weeds is sufficient to maintain the culture without showing negative interference, which can be performed during the predesiccation sowing.

Key words: Phytosociology. Weeds. Interference periods.

\section{INTRODUÇÃO}

No Brasil a produção de biodiesel encontra-se embasada em culturas anuais cultivadas na safra (primavera/verão), faltando alternativas para o cultivo em outono/inverno que possibilita a continuidade da produção de biodiesel, além da inclusão em programas de rotação de culturas (JASPER et al., 2010). Neste contexto, a cultura do crambe se enquadra como uma opção para o cultivo em segunda safra, com potencial para produção de biodiesel.

A cultura do crambe destaca-se por apresentar rusticidade e precocidade, sendo capaz de desenvolver-se em condições climáticas adversas, suportando desde geadas até climas quentes e secos, e apresenta baixo custo de produção, florescimento aos 35 dias após a semeadura, com 35 a 60\% de óleo (PITOL et al., 2010b).

O cultivo da cultura do crambe pode ser influenciado pela presença da comunidade infestante, porém ainda não há pesquisas com períodos de interferência e convivência para esta cultura. O grau de competição na associação plantas daninhas-cultura depende da intervenção de fatores ligados tanto à comunidade infestante (composição específica, densidade e distribuição) quanto à própria cultura (espécie, espaçamento e densidade), apresentando alterações em função do tempo de convivência, das condições edafoclimáticas e dos tratos culturais adotados (BLANCO, 1972), da época e extensão do período de convivência (PITELLI, 1985), sendo maior a interferência no início de desenvolvimento da cultura, podendo ocasionar perdas de produtividade (ZAGONEL et al., 2000). 
As determinações dos períodos de convivência tolerados por uma cultura com as plantas daninhas são obtidas estudando-se os períodos de interferência os quais se constitui de: PAI (Período Anterior a Interferência) - período em que as plantas daninhas podem conviver com a cultura sem acarretar em redução na produtividade, o meio é capaz de fornecer os fatores de crescimento necessários à cultura e às plantas daninhas; PTPI (Período Total de Prevenção a Interferência) - período em que a cultura deve crescer livre da presença de plantas daninhas, para que a sua produtividade não seja afetada; e PCPI (Período Crítico de Prevenção a Interferência) - período em que as práticas de controle devem ser adotadas (PITELLI e DURIGAN, 1984). Com a determinação dos períodos de convivência entre cultura e plantas daninhas, pode-se estabelecer o momento mais adequado para realizar o manejo de plantas daninhas na cultura.

Neste contexto, torna-se importante conhecer a interferência imposta pelas plantas daninhas à cultura. Então, objetivou-se determinar os períodos de convivência e controle entre plantas daninhas e a cultura de crambe, cultivado na estação primavera/verão (safra) e na estação de outono (safrinha).

\section{MATERIAL E MÉTODOS}

Em campo, foram conduzidos dois experimentos com a cultura de crambe (Crambe abyssinica), os quais foram instalados na estação primavera/verão (safra) e no verão/outono (safrinha) no ano agrícola 2011-12, em uma região com altitude de cerca de $700 \mathrm{~m}$ e precipitação pluviométrica anual de $1800 \mathrm{~mm}$, distribuída entre os meses de Setembro a Abril. O solo da área experimental foi classificado como Latossolo Vermelho distroférrico, de textura argilosa (EMBRAPA, 2006). Os dados climatológicos do período de condução da pesquisa (Figura 1) foram obtidos em estação agrometeorológica do INMET (Instituto Nacional de meteorologia), lotada a $1000 \mathrm{~m}$ da área experimental.

No cultivo de safrinha, o crambe foi semeado em 18/03/2011 e colhido em 17/06/2011 e no cultivo de safra, o crambe foi semeado em 21/10/2011 e colhido em 20/01/2012. A cultivar de crambe adotada foi a FMS Brilhante, desenvolvida pela Fundação Mato Grosso do Sul.

O delineamento experimental adotado foi o de blocos casualizados (DBC), com quatro repetições. Os tratamentos foram constituídos por dois grupos: período de controle (períodos crescentes da cultura mantida no limpo) e período de convivência das plantas daninhas com o crambe (períodos crescentes da cultura mantida no mato). Cada parcela experimental foi composta por 7 linhas de semeadura de crambe espaçadas em 0,45 m e com 5 metros de comprimento. Como área útil de cada parcela experimental foram adotadas as três linhas centrais. 


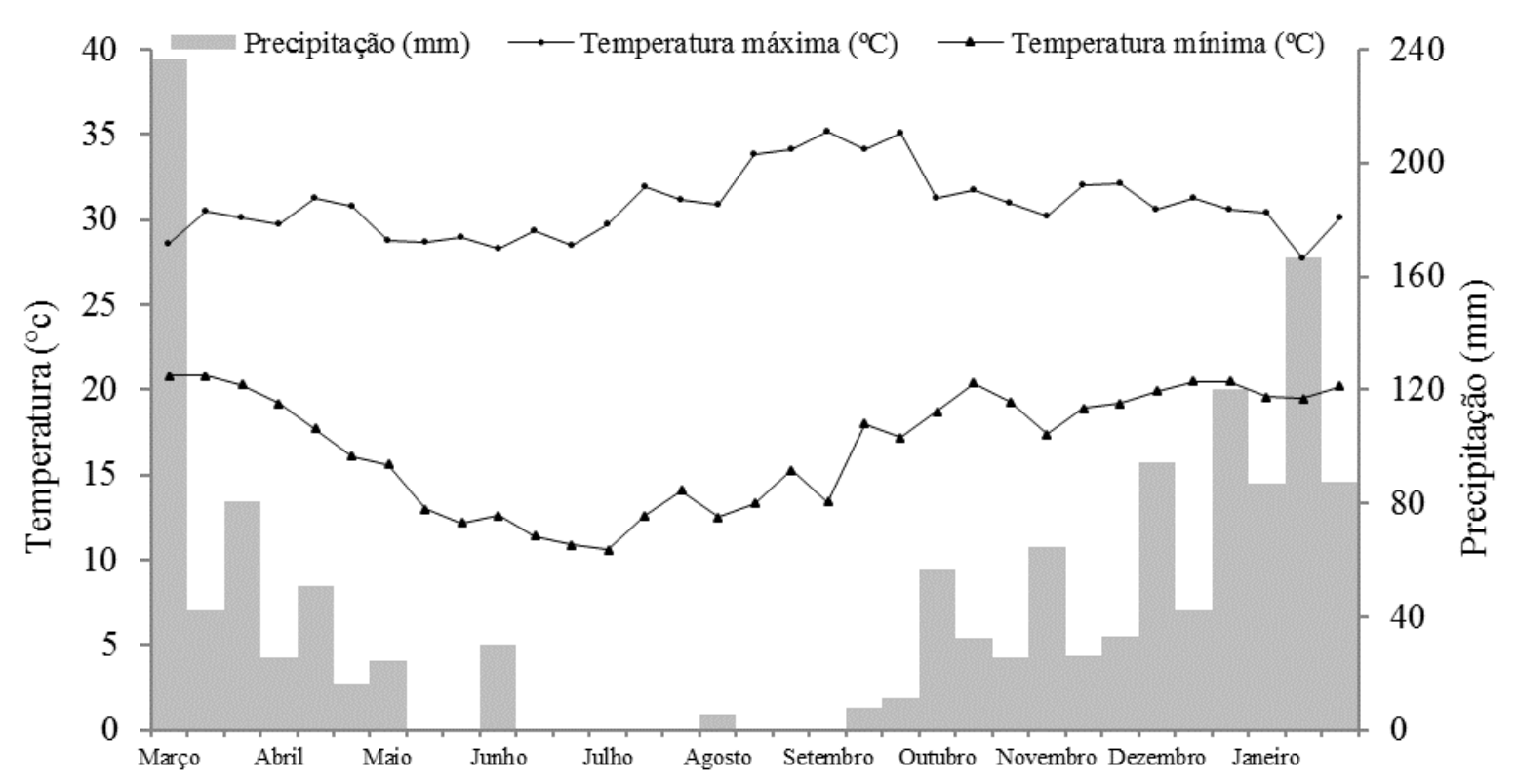

Figura 1. Médias de temperatura máxima e mínima do ar e total de precipitações, em decêndios, durante o período de condução da pesquisa. (INMET, 2011).

No período de controle, os tratamentos foram compostos pela cultura mantida livre de plantas daninhas nos períodos de $0,7,14,21,28,35,42,56$ e 70 dias após a semeadura (DAS). As plantas daninhas que emergiram após cada período não foram controladas até a colheita. No período de convivência, a cultura foi mantida na presença das plantas daninhas nos mesmos períodos citados anteriormente e sem plantas daninhas até a colheita a partir do período citado. O controle das plantas daninhas ao final de cada período proposto foi realizado por meio de capina manual.

Nos dois experimentos foi utilizado o sistema de plantio direto e, para tanto, foi realizada dessecação da área aos sete dias antes da semeadura, com glyphosate a 1,44 kg e. a. ha ${ }^{-1}$. As sementes foram tratadas com uma combinação do inseticida CropStar ${ }^{\circledR}$ (tiodicarbe + imidacloprido) e do fungicida Derosal Plus ${ }^{\circledR}$ (tiram + carbendazim) nas doses de 0,5 e $0,2 \mathrm{~L}$, respectivamente, para cada $100 \mathrm{~kg}$ de sementes. No cultivo de safra foi realizada uma adubação a lanço com $360 \mathrm{~kg} \mathrm{ha}^{-1}$ do formulado 02-20-18. No cultivo de safrinha não foi realizada adubação, adotando-se somente os resíduos da adubação realizada para a soja cultivada anteriormente. Durante o cultivo de safra, aos 50 DAS, foi realizada uma aplicação do fungicida Priori $\mathrm{Xtra}^{\circledR}{ }^{\circledR}$ (triazol + estrobilurina) visando o controle de Alternaria sp., na dose de $0,3 \mathrm{~L} \mathrm{ha}^{-1}$. Durante o cultivo de safrinha foi realizada uma aplicação aos 24 DAS do inseticida Engeo Pleno ${ }^{\circledR}$ (tiametoxam + lambda-cialotrina), visando o controle de Cerotoma sp., na dose de $0,12 \mathrm{~L} \mathrm{ha}^{-1}$.

Na caracterização da comunidade de plantas daninhas realizadas por época do manejo proposto, foram amostradas, em cada unidade experimental, de forma aleatória, cinco áreas de 0,20 x 0,50m ao final de cada período. Nestas avaliações, as plantas daninhas foram identificadas, contadas e cortadas rente ao solo; as mesmas foram acondicionadas em sacos 
de papel e submetidas à secagem em câmara de circulação forçada de ar a $70^{\circ} \mathrm{C}$, até atingirem massa constante.

Os dados relativos a cada espécie de planta daninha foram utilizados para determinação dos índices fitossociológicos, de acordo com as fórmulas propostas por Müeller-Dombois e Ellenberg (1974). Os índices fitossociológicos determinados foram: Densidade (D), número total de indivíduos de uma população por unidade de área; Variância $\left(\sigma^{2}\right)$; e Índice de Valor de Importância (IVI), o qual foi obtido pelo somatório da constância relativa (Co.R.), densidade relativa (De.R.) e dominância relativa (Do.R.). O IVI determina as espécies de maior importância dentro da comunidade de plantas.

Na cultura de crambe foi determinado o estande de plantas aos 45 DAS, a altura de plantas no período pré-colheita e a produtividade de síliquas. Para a avaliação do estande de plantas foi realizada a contagem do número de plantas presentes nas duas linhas centrais, com 2,5 metros, totalizando 5 metros. Para obtenção da média de altura de plantas foi tomada ao acaso 10 plantas dentro da área útil de cada parcela, medindo-se do colo ao ápice da haste principal das plantas. Para determinação da produtividade de síliquas foram colhidas as plantas existentes em 2,5m de comprimento, nas duas linhas centrais.

Para os índices fitossociológicos foi adotada a análise descritiva. Para os dados de estande de plantas, altura de plantas e produtividade de síliquas foi adotada análise de variância pelo teste $\mathrm{F}$ e, posteriormente, quando significativo, à comparação de médias pelo teste de Tukey a 5\% de probabilidade (BANZATO e KRONKA, 2006). O programa estatístico utilizado foi o software Assistat.

\section{RESULTADOS E DISCUSSÃO}

As plantas daninhas presentes na área experimental, nos cultivos de safra e safrinha, são listadas na Tabela 1. Durante a safra, a principal família botânica foi a Poaceae, representada por $50 \%$ das espécies presentes na comunidade de plantas daninhas, evidenciando o alto grau de competição das espécies pertencentes a esta família. Observouse também a presença de sorgo voluntário (tiguera), proveniente do banco de sementes, remanescente do cultivo de safrinha do ano anterior. Já no cultivo em safrinha, o número de espécies pertencentes à família Poaceae não superou 20\% do total. Neste período de cultivo houve maior diversidade na composição da comunidade de plantas daninhas, constatando também a presença de Conyza canadensis e Amaranthus viridis, as quais não ocorreram no cultivo de safra.

No cultivo de crambe na safra, nos períodos de controle, as plantas daninhas que apresentaram maior índice de valor de importância (IVI) foram o sorgo (Sorghum bicollor) e a erva-de-santa-luzia (Chamaesyce hirta). Com menor índice de valor de importância ocorreram as espécies trapoeraba (Commelina benghalensis), capim-custódio (Pennisetum setosum) e picão-preto (Bidens pilosa) (Tabela 2). 
Tabela 1. Relação de plantas daninhas presentes na área experimental, no cultivo de crambe na safra e safrinha, identificadas por família, espécie, nome comum e código internacional.

\begin{tabular}{llll}
\hline CRAMBE SAFRA & & \\
\hline Família & Espécie & Nome comum & Código \\
\hline \multirow{4}{*}{ Poaceae } & Digitaria horizontalis & Capim-colchão & DIGHO \\
& Cenchrus echinatus & Capim-carrapicho & CCHEC \\
& Pennisetum setosum & Capim-custódio & PESSE \\
& Sorghum bicollor & Sorgo Resteva & SORSS \\
\hline \multirow{2}{*}{ Euphorbiaceae } & Chamaesyce hirta & Erva-de-santa-luzia & EPHHI \\
& Euphorbia heterophylla & Leiteiro & EPHHL \\
\hline Asteraceae & Bidens pilosa & Picão-preto & BIDPI \\
\hline Commelinaceae & Commelina benghalensis & Trapoeraba & COMBE \\
\hline CRAMBE SAFRINHA & & Nome comum & Codigo \\
\hline Família & Espécie & Capim-colchão & DIGHO \\
\multirow{2}{*}{ Poaceae } & Cenchrus echinatus & Capim-carrapicho & CCHEC \\
\hline \multirow{2}{*}{ Euphorbiaceae } & Chamaesyce hirta & Erva-de-santa-luzia & EPHHI \\
& Euphorbia heterophylla & Leiteiro & EPHHL \\
\hline \multirow{2}{*}{ Asteraceae } & Bidens pilosa & Picão-preto & BIDPI \\
\cline { 2 - 4 } & Conyza canadensis & Buva & ERICA \\
\hline Amaranthaceae & Amaranthus viridis & Caruru-de-mancha & AMAVI \\
\hline Malvaceae & Sida rhombifolia & Guanxuma & SIDRH \\
\hline Commelinaceae & Commelina benghalensis & Trapoeraba & COMBE \\
\hline
\end{tabular}

No período de safrinha, as plantas daninhas que obtiveram maior índice de valor de importância (IVI) foram a erva-de-santa-luzia (Chamaesyce hirta) e capim-colchão (Digitaria horizontalis), nos diferentes períodos de controle, mostrando que estas plantas daninhas são adaptadas a condições edafoclimáticas da área. Com menor índice de valor de importância ocorreram as plantas de soja tiguera (Glycine max), capim-carrapicho (Cenchrus echinatus), guanxuma (Sida rhombifolia), buva (Conyza canadensis) e caruru-demancha (Amaranthus viridis) (Tabela 2).

Tabela 2. Densidade (Plantas $\mathrm{m}^{-2}$ ), variância e índice de valor de importância das espécies de plantas daninhas componentes da comunidade infestante, nos períodos de controle com a cultura de crambe de safra e safrinha, avaliada na colheita.

\begin{tabular}{|c|c|c|c|c|c|c|}
\hline \multirow{2}{*}{$\begin{array}{l}\text { Espécies de } \\
\text { Plantas Daninhas }\end{array}$} & Densidade & Variância & IVI & Densidade & Variância & IVI \\
\hline & \multicolumn{3}{|c|}{ Safra } & \multicolumn{3}{|c|}{ Safrinha } \\
\hline \multicolumn{7}{|c|}{0 dias após a semeadura } \\
\hline BIDPI & 1,5 & 1,67 & 16,01 & - & - & - \\
\hline Sorgo & 8,3 & 2,92 & 120,94 & - & - & - \\
\hline COMBE & 6,0 & 4,67 & 38,26 & - & - & - \\
\hline PESSE & 4,0 & 0,67 & 52,46 & - & - & - \\
\hline EPHHI & 27,8 & 186,25 & 72,33 & 3,0 & 3,33 & 136,92 \\
\hline DIGHO & - & - & - & 2,0 & 6,00 & 83,10 \\
\hline Soja & - & - & - & 0,8 & 2,25 & 32,08 \\
\hline $\mathrm{CCHEC}$ & - & - & - & 0,8 & 2,25 & 47,91 \\
\hline
\end{tabular}


Tabela 2. Continuação...

\begin{tabular}{|c|c|c|c|c|c|c|}
\hline \multirow{2}{*}{$\begin{array}{l}\text { Espécies de } \\
\text { Plantas Daninhas }\end{array}$} & Densidade & Variância & IVI & Densidade & Variância & IVI \\
\hline & \multicolumn{3}{|c|}{ Safra } & \multicolumn{3}{|c|}{ Safrinha } \\
\hline \multicolumn{7}{|c|}{7 dias após a semeadura } \\
\hline Sorgo & 3,0 & 0,67 & 96,48 & - & - & - \\
\hline COMBE & 4,0 & 0,67 & 43,02 & - & - & - \\
\hline PESSE & 1,8 & 0,92 & 36,66 & - & - & - \\
\hline DIGHO & 2,3 & 1,58 & 29,76 & 2,3 & 2,25 & 98,71 \\
\hline EPHHI & 12,3 & 60,25 & 72,80 & 6,5 & 27,00 & 154,25 \\
\hline Soja & - & - & - & 0,5 & 1,00 & 26,15 \\
\hline SIDRH & - & - & - & 0,3 & 0,25 & 20,88 \\
\hline \multicolumn{7}{|c|}{14 dias após a semeadura } \\
\hline BIDPI & 1,3 & 2,25 & 25,57 & - & - & - \\
\hline Sorgo & 2,3 & 2,92 & 71,92 & - & - & - \\
\hline COMBE & 3,0 & 0,67 & 47,36 & - & - & - \\
\hline PESSE & 1,3 & 0,92 & 49,13 & - & - & - \\
\hline EPHHI & 8,8 & 8,92 & 83,79 & 1,9 & 3,58 & 143,45 \\
\hline DIGHO & - & - & - & 0,9 & 4,00 & 123,70 \\
\hline CCHEC & - & - & - & 0,5 & 0,25 & 18,88 \\
\hline \multicolumn{7}{|c|}{21 dias após a semeadura } \\
\hline BIDPI & 0,8 & 0,92 & 16,01 & - & - & - \\
\hline Sorgo & 6,5 & 21,67 & 120,94 & - & - & - \\
\hline COMBE & 1,8 & 0,92 & 38,26 & - & - & - \\
\hline PESSE & 2,8 & 3,58 & 52,46 & - & - & - \\
\hline EPHHI & 8,8 & 0,92 & 72,33 & 1,8 & 64,67 & 187,27 \\
\hline DIGHO & - & - & - & 1,1 & 7,58 & 112,73 \\
\hline \multicolumn{7}{|c|}{28 dias após a semeadura } \\
\hline BIDPI & 1,3 & 3,58 & 27,88 & - & - & - \\
\hline Sorgo & 2,5 & 3,67 & 86,51 & - & - & - \\
\hline COMBE & 1,8 & 0,92 & 45,90 & - & - & - \\
\hline PESSE & 1,8 & 4,25 & 50,53 & - & - & - \\
\hline EPHHI & 6,5 & 5,67 & 81,01 & 2,8 & 5,58 & 238,00 \\
\hline DIGHO & - & - & - & 0,5 & 1,00 & 62,00 \\
\hline \multicolumn{7}{|c|}{35 dias após a semeadura } \\
\hline BIDPI & 1,3 & 3,58 & 28,04 & - & - & - \\
\hline COMBE & 2 & 0,67 & 59,56 & - & - & - \\
\hline PESSE & 2,8 & 4,92 & 104,30 & - & - & - \\
\hline Sorgo & 2,5 & 3,21 & 73,51 & - & - & - \\
\hline EPHHI & 7,5 & 11,67 & 108,10 & 2,5 & 7,00 & 264,17 \\
\hline ERICA & - & - & - & 0,3 & 0,25 & 35,83 \\
\hline \multicolumn{7}{|c|}{42 dias após a semeadura } \\
\hline BIDPI & 0,5 & 0,33 & 33,13 & - & - & - \\
\hline COMBE & 1 & 0,67 & 63,19 & - & - & - \\
\hline PESSE & 0,5 & 1,00 & 50,17 & - & - & - \\
\hline CCHEC & 0,3 & 0,25 & 17,82 & - & - & - \\
\hline EPHHI & 2,5 & 7,00 & 135,70 & 3,5 & 0,33 & 268,44 \\
\hline DIGHO & - & - & - & 0,3 & 0,25 & 31,56 \\
\hline
\end{tabular}


Tabela 2. Continuação...

\begin{tabular}{|c|c|c|c|c|c|c|}
\hline Espécies de & Densidade & Variância & IVI & Densidade & Variância & IVI \\
\hline Plantas Daninhas & & Safra & & & Safrinha & \\
\hline \multicolumn{7}{|c|}{56 dias após a semeadura } \\
\hline Sorgo & 0,3 & 0,25 & 79,54 & - & - & - \\
\hline COMBE & 1,5 & 1,67 & 56,46 & - & - & - \\
\hline PESSE & 1,8 & 2,92 & 57,49 & - & - & - \\
\hline CCHEC & 0,3 & 0,25 & 13,93 & - & - & - \\
\hline EPHHI & 3,3 & 6,25 & 92,58 & 1,5 & 1,67 & 189,56 \\
\hline DIGHO & - & - & - & 0,3 & 0,25 & 29,98 \\
\hline Soja & - & - & - & 0,3 & 0,25 & 36,89 \\
\hline AMAVI & - & - & - & 0,5 & 1,00 & 43,57 \\
\hline \multicolumn{7}{|c|}{70 dias após a semeadura } \\
\hline COMBE & 0,3 & 0,25 & 33,84 & - & - & - \\
\hline PESSE & 0,8 & 2,25 & 53,77 & - & - & - \\
\hline EPHHI & 1,8 & 12,25 & 125,09 & - & - & - \\
\hline
\end{tabular}

Tabela 3. Densidade (Plantas $\mathrm{m}^{-2}$ ), variância e índice de valor de importância das espécies de plantas daninhas componentes da comunidade infestante, nos períodos de convivência com a cultura de crambe de safra e safrinha, avaliada no final de cada período.

\begin{tabular}{|c|c|c|c|c|c|c|}
\hline \multirow{2}{*}{$\begin{array}{l}\text { Espécies de Plantas } \\
\text { Daninhas }\end{array}$} & Densidade & Variância & IVI & Densidade & Variância & IVI \\
\hline & \multicolumn{3}{|c|}{ Safra } & \multicolumn{3}{|c|}{ Safrinha } \\
\hline \multicolumn{7}{|c|}{0 e 7 dias após a semeadura } \\
\hline \multicolumn{7}{|c|}{ Ausência de Plantas Daninhas } \\
\hline \multicolumn{7}{|c|}{14 dias após a semeadura } \\
\hline Sorgo & & & & - & - & - \\
\hline COMBE & & & & - & - & - \\
\hline $\mathrm{CCHEC}$ & - & - & - & 0,3 & 0,25 & 37,19 \\
\hline EPHHL & - & - & - & 0,3 & 0,25 & 32,02 \\
\hline BIDPI & - & - & - & 0,3 & 0,25 & 32,02 \\
\hline Soja & - & - & - & 0,8 & 0,25 & 158,13 \\
\hline EPHHI & - & - & - & 0,3 & 0,25 & 40,64 \\
\hline \multicolumn{7}{|c|}{21 dias após a semeadura } \\
\hline BIDPI & & & & 0,3 & 0,25 & 14,87 \\
\hline Sorgo & & & & - & - & - \\
\hline COMBE & & & & - & - & - \\
\hline CCHEC & - & - & - & 0,8 & 0,92 & 27,32 \\
\hline DIGHO & - & - & - & 2,8 & 17,58 & 75,98 \\
\hline Soja & - & - & - & 0,5 & 0,33 & 83,48 \\
\hline EPHHI & - & - & - & 1,3 & 0,25 & 50,80 \\
\hline
\end{tabular}


Tabela 3. Continuação...

\begin{tabular}{|c|c|c|c|c|c|c|}
\hline \multirow{2}{*}{$\begin{array}{l}\text { Espécies de Plantas } \\
\text { Daninhas }\end{array}$} & Densidade & Variância & IVI & Densidade & Variância & IVI \\
\hline & \multicolumn{3}{|c|}{ Safra } & \multicolumn{3}{|c|}{ Safrinha } \\
\hline \multicolumn{7}{|c|}{28 dias após a semeadura } \\
\hline DIGHO & 2,0 & 2,00 & 36,73 & - & - & - \\
\hline BIDPI & 1,3 & 3,58 & 21,35 & - & - & - \\
\hline Sorgo & 5,0 & 8,67 & 91,11 & - & - & - \\
\hline COMBE & 8,3 & 57,58 & 84,36 & - & - & - \\
\hline EPHHI & 2,3 & 2,25 & 31,56 & 7,3 & 2,92 & 139,82 \\
\hline Soja & - & - & - & 0,5 & 0,33 & 22,05 \\
\hline ERICA & - & - & - & 0,3 & 0,25 & 9,63 \\
\hline CCHEC & - & - & - & 0,5 & 0,33 & 19,51 \\
\hline \multicolumn{7}{|c|}{35 dias após a semeadura } \\
\hline DIGHO & 12,5 & 137,58 & 75,63 & 6,5 & 23,00 & 97,26 \\
\hline BIDPI & 1,3 & 6,25 & 15,86 & - & - & - \\
\hline Sorgo & 4,5 & 15,00 & 83,98 & - & - & - \\
\hline EPHHI & 2,0 & 4,00 & 27,72 & 6,0 & 34,67 & 62,79 \\
\hline CCHEC & 5,0 & 31,33 & 39,42 & 4,0 & 30,00 & 54,89 \\
\hline Soja & - & - & - & 2,5 & 9,67 & 47,40 \\
\hline AMAVI & - & - & - & 0,8 & 0,92 & 16,15 \\
\hline \multicolumn{7}{|c|}{42 dias após a semeadura } \\
\hline DIGHO & 2,8 & 6,25 & 25,97 & 2,8 & 4,92 & 59,56 \\
\hline Sorgo & 4,0 & 3,33 & 81,79 & - & - & - \\
\hline COMBE & 8,5 & 206,33 & 46,85 & - & - & - \\
\hline EPHHI & 5,3 & 64,92 & 26,11 & 19,8 & 854,25 & 163,50 \\
\hline CCHEC & 11,8 & 339,58 & 53,54 & 1,3 & 1,58 & 27,93 \\
\hline BIDPI & - & - & - & 0,3 & 0,25 & 10,13 \\
\hline Soja & - & - & - & 0,5 & 0,33 & 22,37 \\
\hline \multicolumn{7}{|c|}{56 dias após a semeadura } \\
\hline BIDPI & 0,7 & 0,92 & 14,71 & 0,3 & 0,25 & 10,09 \\
\hline Sorgo & 5,5 & 3,00 & 101,40 & - & - & - \\
\hline COMBE & 8,3 & 14,92 & 59,07 & - & - & - \\
\hline EPHHI & 8,3 & 4,25 & 58,74 & 13,5 & 156,33 & 104,16 \\
\hline CCHEC & 0,3 & 0,25 & 6,48 & 0,5 & 1,00 & 27,65 \\
\hline DIGHO & - & - & - & 5,0 & 14,00 & 72,18 \\
\hline Soja & - & - & - & 1,8 & 0,92 & 57,60 \\
\hline
\end{tabular}


Tabela 3. Continuação...

\begin{tabular}{lllllll}
\hline \multirow{2}{*}{$\begin{array}{l}\text { Espécies de Plantas } \\
\text { Daninhas }\end{array}$} & Densidade & Variância & IVI & Densidade & Variância & IVI \\
\cline { 2 - 6 } & \multicolumn{5}{c}{ Safra } \\
\hline \multicolumn{7}{l}{ 70 dias após a semeadura } \\
\hline DIGHO & 2,0 & 16,00 & 15,74 & 3,3 & 7,58 & 88,66 \\
BIDPI & 2,5 & 7,00 & 29,29 & - & - & - \\
Sorgo & 7,5 & 4,33 & 94,82 & - & - & - \\
COMBE & 12,8 & 14,92 & 62,34 & 0,3 & 0,25 & 9,38 \\
EPHHI & 11,3 & 2,92 & 56,78 & 8,5 & 46,33 & 115,02 \\
Soja & - & - & - & 1,0 & 2,00 & 41,06 \\
CCHEC & - & - & - & 1,0 & 0,67 & 30,61 \\
\hline
\end{tabular}

Nos períodos de convivência, no cultivo de crambe na safra, as plantas daninhas que apresentaram maior índice de valor de importância foram sorgo (Sorghum bicollor) e trapoeraba (Commelina benghalensis). Já no cultivo de safrinha, as plantas daninhas soja resteva (Glycine max), erva-de-santa-luzia (Chamaesyce hirta) e capim-colchão (Digitaria horizontalis) apresentaram maior índice de valor de importância (Tabela 3).

Com o aumento do período de convivência entre a cultura do crambe e as plantas daninhas há uma redução na densidade de plantas daninhas, o que deve ter ocorrido em função do desenvolvimento das plantas de crambe, potencializando o poder de competição das mesmas. Segundo Souza Júnior et al. (2010), quando ocorre maior ocupação de área pelas plantas da cultura (competição intraespecífica), a competição entre a cultura e as plantas daninhas é menor. Assim, no caso de adoção de menor espaçamento de cultivo de crambe aumentará ainda mais a vantagem para a cultura em relação à comunidade infestante.

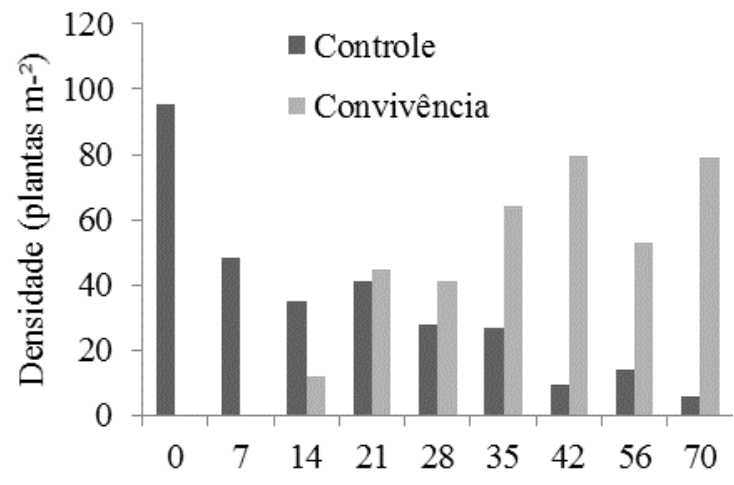

(A)

Dias após a semeadura

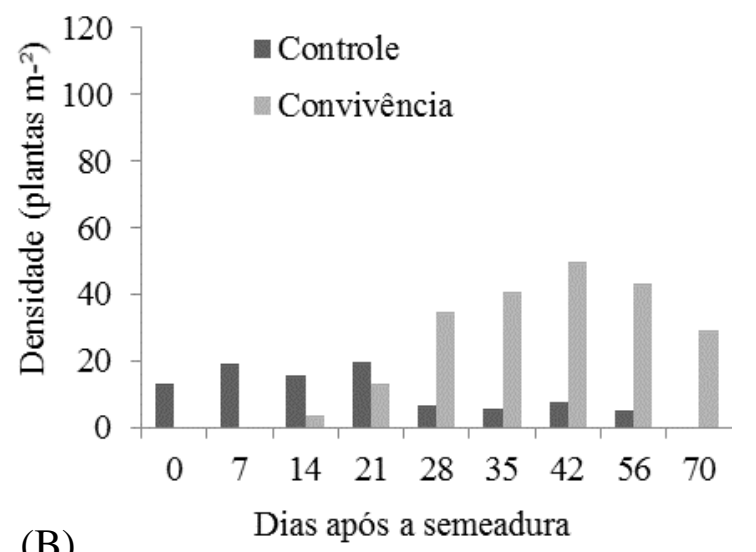

(B)

Figura 2. Densidade total de plantas daninhas (plantas $\mathrm{m}^{-2}$ ) referentes aos períodos de controle e convivência, durante o cultivo da cultura de crambe nos períodos de safra (A) e safrinha (B).

Na Figura 2 são apresentados os dados referentes à densidade total de plantas daninhas nos tratamentos que compuseram os períodos de controle e de convivência durante 
os cultivos de safra (A) e safrinha (B). Observou-se que durante o período de safra a densidade de plantas daninhas foi superior ao do período de safrinha, nos diferentes períodos de controle e de convivência. Isso ocorreu possivelmente devido às condições climáticas (precipitação, luz, temperatura) mais favoráveis ao desenvolvimento das plantas, contribuindo assim para maior densidade da comunidade infestante além de maior desenvolvimento vegetativo e reprodutivo da comunidade infestante de plantas daninhas (Figura 3).

O acúmulo de massa seca pelas plantas daninhas na safra (A) superou em aproximadamente dez vezes o observado na safrinha (B) (Figura 3). Pode-se constatar que o acúmulo de massa seca de plantas daninhas possui uma correlação com os dados de densidade (Figura 2), ou seja, conforme há o aumento da densidade de plantas daninhas observa-se o aumento no acúmulo de massa seca das plantas daninhas.

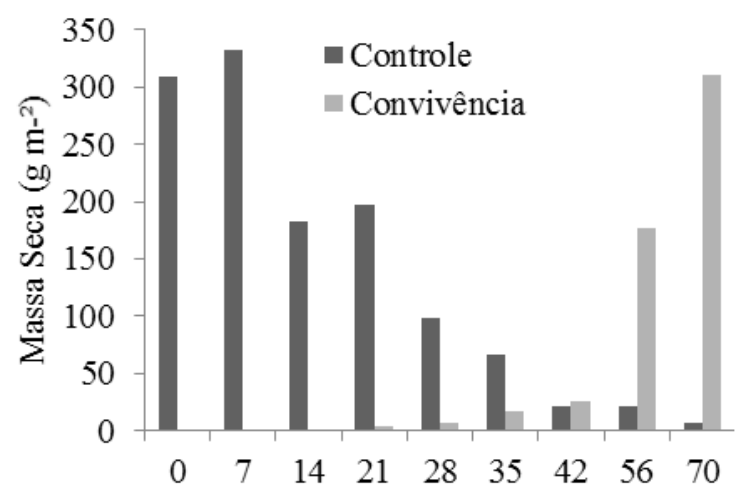

(A) Dias após a semeadura

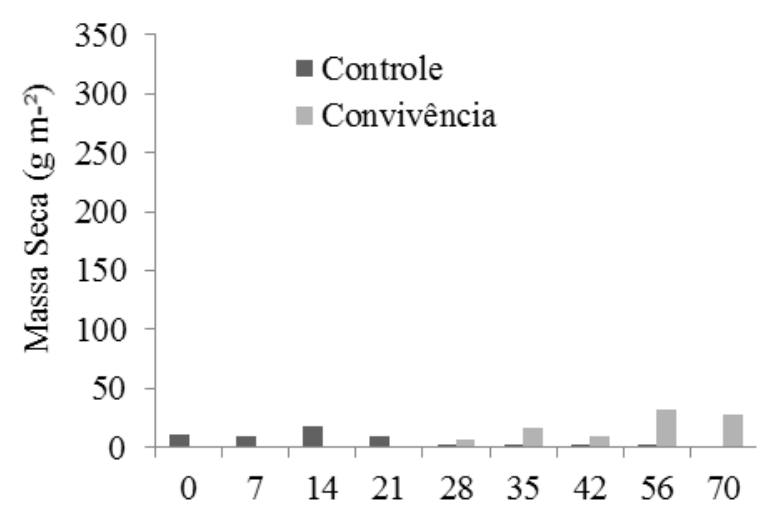

(B)

Dias após a semeadura

Figura 3. Massa seca de plantas daninhas $\left(\mathrm{g} \mathrm{m}^{-2}\right)$ referentes aos períodos de controle e convivência, durante o cultivo da cultura de crambe nos períodos de safra (A) e safrinha (B).

Quanto ao estande de plantas de crambe, não houve diferença entre os efeitos dos períodos de controle e de convivência (Tabela 4). Em ambas as situações, a população de plantas de crambe foi, em média, de 730 mil plantas ha $^{-1}$. Tal população se adéqua ao recomendado por Pitol et al. (2010b). A baixa influência da comunidade infestante de plantas daninhas no estabelecimento da cultura consolida o alto grau de competitividade do crambe em relação às plantas daninhas. De acordo com Blanco (1972) e Pitelli (1985), a interferência das plantas daninhas altera em maior proporção a produtividade de grãos por indivíduo do que a sobrevivência das plantas. As perdas de produtividade podem ser maiores em culturas que não perfilham, as quais não possuem poder de compensação de produção. 
Tabela 4. Estande de plantas de crambe (plantas $\mathrm{m}^{-1}$ ), nos cultivos de safra e safrinha, determinado aos 45 dias após a semeadura, em resposta aos períodos de controle e convivência.

\begin{tabular}{lcccc}
\hline \multirow{2}{*}{$\begin{array}{l}\text { Dias após a } \\
\text { semeadura }\end{array}$} & \multicolumn{2}{c}{ Estande (plantas $\left.\mathrm{m}^{-1}\right)$} & \multicolumn{2}{c}{$\begin{array}{c}\text { Estande }\left(\text { plantas } \mathrm{m}^{-1}\right) \\
\text { Safra }\end{array}$} \\
\cline { 2 - 5 } & $\begin{array}{c}\text { Período de } \\
\text { Controle }\end{array}$ & $\begin{array}{c}\text { Período de } \\
\text { Convivência }\end{array}$ & $\begin{array}{c}\text { Período de } \\
\text { Controle }\end{array}$ & $\begin{array}{c}\text { Período de } \\
\text { Convivência }\end{array}$ \\
\hline 0 & $33,35 \mathrm{a}$ & $32,90 \mathrm{a}$ & $36,15 \mathrm{a}$ & $35,06 \mathrm{a}$ \\
7 & $32,70 \mathrm{a}$ & $31,85 \mathrm{a}$ & $31,93 \mathrm{a}$ & $31,35 \mathrm{a}$ \\
14 & $30,90 \mathrm{a}$ & $33,05 \mathrm{a}$ & $31,35 \mathrm{a}$ & $31,93 \mathrm{a}$ \\
21 & $30,18 \mathrm{a}$ & $33,10 \mathrm{a}$ & $35,30 \mathrm{a}$ & $34,20 \mathrm{a}$ \\
28 & $32,65 \mathrm{a}$ & $32,10 \mathrm{a}$ & $33,33 \mathrm{a}$ & $33,32 \mathrm{a}$ \\
35 & $32,95 \mathrm{a}$ & $32,55 \mathrm{a}$ & $32,32 \mathrm{a}$ & $33,70 \mathrm{a}$ \\
42 & $32,05 \mathrm{a}$ & $34,10 \mathrm{a}$ & $37,80 \mathrm{a}$ & $35,92 \mathrm{a}$ \\
56 & $31,25 \mathrm{a}$ & $30,50 \mathrm{a}$ & $35,90 \mathrm{a}$ & $34,20 \mathrm{a}$ \\
70 & $33,60 \mathrm{a}$ & $30,80 \mathrm{a}$ & $38,60 \mathrm{a}$ & $34,58 \mathrm{a}$ \\
\hline F & $2,42 *$ & $1,31^{\mathrm{ns}}$ & $0,37^{\mathrm{ns}}$ & $0,40^{\mathrm{ns}}$ \\
DMS & 8,12 & 6,06 & 9,26 & 8,72 \\
CV $(\%)$ & 9,71 & 7,46 & 11,98 & 11,23 \\
\hline
\end{tabular}

Médias seguidas pela mesma letra na coluna não diferem entre si ao nível de 5\% de significância, pelo teste de Tukey. ${ }^{*}$ Significativo ao nível de 5\% de significância. ${ }^{\text {ns }}$ Não significativo ao nível de 5\% de significância.

Tabela 5. Altura de plantas de crambe $(\mathrm{cm})$, nos cultivos de safra e safrinha, determinada no período pré-colheita, em resposta aos períodos de controle e convivência.

\begin{tabular}{llccc}
\hline \multirow{2}{*}{$\begin{array}{l}\text { Dias após a } \\
\text { semeadura }\end{array}$} & \multicolumn{2}{c}{ Sltura de plantas $(\mathrm{cm})$} & \multicolumn{2}{c}{$\begin{array}{c}\text { Altura de plantas }(\mathrm{cm}) \\
\text { Safrinha }\end{array}$} \\
\cline { 2 - 5 } & $\begin{array}{c}\text { Período de } \\
\text { Controle }\end{array}$ & $\begin{array}{c}\text { Período de } \\
\text { Convivência }\end{array}$ & $\begin{array}{c}\text { Período de } \\
\text { Controle }\end{array}$ & $\begin{array}{c}\text { Período de } \\
\text { Convivência }\end{array}$ \\
\hline 0 & $88,47 \mathrm{a}$ & $90,73 \mathrm{a}$ & $99,60 \mathrm{a}$ & $108,3 \mathrm{a}$ \\
7 & $92,58 \mathrm{a}$ & $92,38 \mathrm{a}$ & $103,0 \mathrm{a}$ & $101,4 \mathrm{a}$ \\
14 & $91,80 \mathrm{a}$ & $86,08 \mathrm{a}$ & $100,3 \mathrm{a}$ & $104,2 \mathrm{a}$ \\
21 & $90,48 \mathrm{a}$ & $94,53 \mathrm{a}$ & $104,8 \mathrm{a}$ & $106,8 \mathrm{a}$ \\
28 & $88,93 \mathrm{a}$ & $92,90 \mathrm{a}$ & $104,6 \mathrm{a}$ & $104,2 \mathrm{a}$ \\
35 & $95,23 \mathrm{a}$ & $94,25 \mathrm{a}$ & $104,5 \mathrm{a}$ & $102,4 \mathrm{a}$ \\
42 & $93,45 \mathrm{a}$ & $93,55 \mathrm{a}$ & $106,1 \mathrm{a}$ & $103,6 \mathrm{a}$ \\
56 & $90,23 \mathrm{a}$ & $91,75 \mathrm{a}$ & $101,6 \mathrm{a}$ & $103,5 \mathrm{a}$ \\
70 & $88,43 \mathrm{a}$ & $92,18 \mathrm{a}$ & $102,9 \mathrm{a}$ & $101,8 \mathrm{a}$ \\
\hline F & $82^{\text {ns }}$ & $1,47^{\mathrm{ns}}$ & $1,02^{\mathrm{ns}}$ & $62^{\text {ns }}$ \\
DMS & 12,60 & 10,07 & 10,41 & 13,70 \\
CV $(\%)$ & 5,76 & 4,55 & 4,20 & 5,48 \\
\hline
\end{tabular}

Médias seguidas pela mesma letra na coluna não diferem entre si ao nível de 5\% de significância, pelo teste de Tukey. ${ }^{\text {ns }}$ Não significativo ao nível de 5\% de significância.

Em ambos os períodos de interferência e épocas de cultivo não houve diferença na altura de plantas de crambe (Tabela 5). A baixa influência das plantas daninhas no desenvolvimento das plantas de crambe consolida o poder compensativo da cultura em 
situações adversas, sendo propício seu cultivo em safrinha, uma vez que a incidência de doenças foliares e degrana de síliquas é menor. Segundo Pitol et al. (2010a), o melhor desenvolvimento e fechamento da cultura proporciona maior capacidade de competição com as plantas daninhas.

A produtividade de crambe apresentou diferença estatística apenas entre os períodos de convivência (PAI) no cultivo de safra (Tabela 6), justamente quando ocorreu maior densidade de plantas daninhas na área. Constatou-se que quando a cultura permaneceu em convivência por 70 dias com as plantas daninhas houve redução no seu potencial produtivo. Isso indica que apenas uma intervenção na área para o manejo das plantas daninhas já seria suficiente para obter pleno potencial produtivo da cultura. Entretanto, ainda não há herbicidas seletivos registrados para a cultura que atuem em mono e eudicoteledôneas, simultaneamente.

Tabela 6. Produtividade de frutos de crambe $\left(\mathrm{kg} \mathrm{ha}^{-1}\right)$, nos cultivos de safra e safrinha, referente aos períodos de controle e convivência.

\begin{tabular}{|c|c|c|c|c|}
\hline \multirow{2}{*}{$\begin{array}{l}\text { Dias após a } \\
\text { semeadura }\end{array}$} & \multicolumn{2}{|c|}{$\begin{array}{l}\text { Produtividade de Síliqua }\left(\mathrm{kg} \mathrm{ha}^{-1}\right) \\
\text { Safra }\end{array}$} & \multicolumn{2}{|c|}{$\begin{array}{c}\text { Produtividade de Síliqua }\left(\mathrm{kg} \mathrm{ha}^{-1}\right) \\
\text { Safrinha }\end{array}$} \\
\hline & $\begin{array}{c}\text { Período de } \\
\text { Controle }\end{array}$ & $\begin{array}{l}\text { Período de } \\
\text { Convivência }\end{array}$ & $\begin{array}{l}\text { Período de } \\
\text { Controle }\end{array}$ & $\begin{array}{c}\text { Período de } \\
\text { Convivência }\end{array}$ \\
\hline 0 & $907,25 \mathrm{a}$ & $853,00 \mathrm{ab}$ & $1213,00 \mathrm{a}$ & $1354,00 \mathrm{a}$ \\
\hline 7 & $921,75 \mathrm{a}$ & $1040,5 \mathrm{a}$ & $1200,25 \mathrm{a}$ & $1301,75 \mathrm{a}$ \\
\hline 14 & $827,75 \mathrm{a}$ & $942,00 \mathrm{ab}$ & $1063,50 \mathrm{a}$ & $1316,50 \mathrm{a}$ \\
\hline 21 & $872,50 \mathrm{a}$ & $912,75 \mathrm{ab}$ & $1274,50 \mathrm{a}$ & $1251,50 \mathrm{a}$ \\
\hline 28 & $1063,5 \mathrm{a}$ & $973,50 \mathrm{ab}$ & $1215,25 \mathrm{a}$ & $1131,75 \mathrm{a}$ \\
\hline 35 & $998,25 \mathrm{a}$ & $907,50 \mathrm{ab}$ & $1248,75 \mathrm{a}$ & $1288,25 \mathrm{a}$ \\
\hline 42 & $1032,1 \mathrm{a}$ & $917,00 \mathrm{ab}$ & $1154,50 \mathrm{a}$ & $1305,00 \mathrm{a}$ \\
\hline 56 & $1019,3 \mathrm{a}$ & $719,25 \mathrm{ab}$ & $1452,25 \mathrm{a}$ & $1299,75 \mathrm{a}$ \\
\hline 70 & $943,50 \mathrm{a}$ & $659,00 \mathrm{~b}$ & $1097,00 \mathrm{a}$ & $1109,75 \mathrm{a}$ \\
\hline $\mathrm{F}$ & $1,36^{\mathrm{ns}}$ & $3,15^{*}$ & $1,01^{\mathrm{ns}}$ & $1,52^{\mathrm{ns}}$ \\
\hline DMS & 326,42 & 327,54 & 538,98 & 330,23 \\
\hline $\mathrm{CV}(\%)$ & 14,23 & 15,47 & 18,47 & 10,88 \\
\hline
\end{tabular}

Médias seguidas pela mesma letra na coluna não diferem entre si ao nível de 5\% de significância, pelo teste de Tukey. * Significativo ao nível de 5\% de significância. ${ }^{\text {ns }}$ Não significativo ao nível de $5 \%$ de significância.

Nos períodos de controle, nos cultivos de safra e safrinha, e nos períodos de convivência de plantas daninhas, em safrinha, não se obteve diferença na produtividade de frutos do crambe (Tabela 6). Constatou-se, ainda, que o cultivo da cultura em safrinha proporcionou maior produtividade. Tal resultado corrobora Pitol et al. (2010b), que destacam que devido à planta de crambe ser originada do mediterrâneo e ser adaptada a baixa exigência hídrica e a temperaturas mais baixas, o cultivo em safrinha (estação verão/outono) é mais vantajoso, além da pressão de infestação por doenças e plantas daninhas ser menor.

Diante dos resultados obtidos para a cultura de crambe, em ambas as épocas de cultivo, pôde-se observar que a realização de um bom manejo na dessecação das plantas daninhas, para a adoção do plantio direto, já é o suficiente para que não ocorra interferência 
da comunidade infestante no desenvolvimento e na produtividade do crambe, desde que cultivado em safrinha.

\section{CONCLUSÃO}

No cultivo de safra, a cultura do crambe sofre interferência da comunidade de plantas daninhas somente quando convive por mais de 70 dias, para a comunidade infestante de plantas daninhas pesquisada.

A cultura do crambe não sofre interferência da comunidade de plantas daninhas durante o cultivo de safrinha, na competição imposta pelas plantas daninhas presentes nesta pesquisa.

\section{REFERÊNCIAS BIBLIOGRÁFICAS}

BANZATO, D. A.; KRONKA, S. N. Experimentação agrícola. 4. ed. Jaboticabal: Funep, 2006. 237 p.

BLANCO, H. G. A importância dos estudos ecológicos nos programas de controle das plantas daninhas. O Biológico, Campinas, v. 38, n. 10, p.343-350, 1972.

EMPRESA AGROPECUÁRIA BRASILEIRA - EMBRAPA. Sistema brasileiro de classificação de solos. 2. ed. Rio de Janeiro: Centro Nacional de Pesquisa de Solos, 2006. $306 \mathrm{p}$.

JASPER, S. P.; BIAGGIONI, M. A. M.; SILVA, P. R. A.; SEKI, A. S.; BUENO, O. C. Análise energética da cultura do crambe (Crambe abyssinica Hochst) produzida em plantio direto. Engenharia Agrícola, Jaboticabal, v. 30, n. 3, p.395-403, 2010.

MÜELLER-DOMBOIS, D.; ELLEMBERG, H. Aims and methods of vegetation ecology. New York: Willey \& Sons, 1974. 547 p.

PITELLI, R. A.; DURIGAN, J. C. Terminologia para períodos de controle e de convivência de plantas daninhas em culturas anuais e bianuais. In: CONGRESSO BRASILEIRO DE HERBICIDAS E PLANTAS DANINHAS, 15, 1984, Belo Horizonte. Resumos... Piracicaba: SBHED, 1984. p. 37.

PITELLI, R. A. Interferência de plantas daninhas em culturas agrícolas. Informe Agropecuário, Belo Horizonte, v. 11, n. 129, p.16-17, 1985.

PITOL, C.; BROCH, D. L.; ROSCOE, R. Efeito do espaçamento e densidade de plantio sobre a produtividade do crambe cv. FMS brilhante. In: CONGRESSO BRASILEIRO DE MAMONA \& SIMPÓSIO INTERNACIONAL DE OLEAGINOSAS ENERGÉTICAS, 4, 2010, João Pessoa, PB. Anais... Campina Grande: Embrapa Algodão, 2010. CD-ROM. (a)

PITOL, C.; BROCH, D. L.; ROSCOE, R. Tecnologia e produção: Crambe. Maracaju: Fundação MS, 2010. 60 p. (b) 
SOUZA JÚNIOR, N. L.; PARREIRA, M. C.; COSTA, P. L. A. Plantas daninhas na cultura do amendoim em função do espaçamento e densidade de plantas. Agronomía Tropical, Maracay, v. 60, n. 4, p.341-354, 2010.

ZAGONEL, J.; VENÂNCIO, W. S.; KUNZ, R. P. Efeitos de métodos e épocas de controle das plantas daninhas na cultura do milho. Planta Daninha, Viçosa, v. 18, n. 1, p.143-150, 2000. 